\title{
EFFECT OF THE CONTROLLABLE BEARINGS LUBRICATED BY MAGNETICALLY SENSITIVE OIL ON VIBRATION OF RIGID ROTORS
}

\author{
Zapoměl J.", Ferfecki P.**
}

\begin{abstract}
Dynamical properties of hydrodynamic bearings depend of the Sommerfeld number. To avoid rupture of the oil film of heavily loaded bearings or inducing self-excited oscillation of rotors operating at high angular velocities the Sommerfeld number should remain in a certain interval that depends of the bearing size and design. The only parameter that can be changed during the rotor running to adapt the Sommerfeld number and thus the bearing performance to the current operating conditions is the dynamical viscosity. This is offered by application of magnetic fluids as lubricants. This paper reports on a new design concept of a controllable hydrodynamic bearings lubricated by composite liquid. The research is focused on investigation of the possibilities of the control process on the load capacity of the bearings and on the rotor vibration amplitude attenuation.
\end{abstract}

\section{Keywords: Composite magnetic fluids, Controllable hydrodynamic bearing, Rigid rotors, Increase of} the load capacity, Vibration attenuation.

\section{Introduction}

Dynamical properties of hydrodynamic bearings depend of the Sommerfeld number:

$$
S o=\frac{F}{\omega \eta} \frac{4 c^{2}}{L D^{3}}
$$

$F$ is the force loading the bearing, $c$ is the width of the bearing clearance, $L$ is the bearing length, $D$ is the journal diameter, $\omega$ is angular speed of the journal rotation, and $\eta$ is the lubricant dynamical viscosity.

Rising value of the Sommerfeld number increases the rotor journal eccentricity in the bearing (Bolek, 1989). Large eccentricity can cause rupture of the oil film while its low value can induce the rotor selfexcited oscillations. To achieve optimum performance of the hydrodynamic bearing, the Sommerfeld number should be in a certain interval, which depends on the bearing size and design.

Relation (1) shows that if the rotor operates in a wide extent of running speeds and its loading by external forces remains constant the only possibitity how to adapt the rotor journal eccentricity to the current angular velocity is to change dynamical viscosity of the lubricant. This is offered by application of oils, the properties of which are sensitive to a magnetic field.

Wang et al. (2015) reported on suppression of lateral vibration of rotors and on the change of their critical speed by application of magnetorheological fluids as lubricants in hydrodynamic bearings. Several design concepts of ferromagnetic bearings can be found in literature. Nevertheless, it was proved that the ferromagnetic fluids themselves are too weak so that they cannot be used as tunable lubricants to control journal bearings (Urreta, 2010).

\footnotetext{
Prof. Ing. Jaroslav Zapoměl, DSc.: Department of Applied Mechanics, VSB - Technical University of Ostrava, 17. listopadu 15; 708 33, Ostrava; CZ, jaroslav.zapomel@vsb.cz

and Department of Dynamics and Vibration, Institute of Thermomechanics, Dolejškova 5; Prague 8, 182 00; CZ, zapomel@it.cas.cz

** Ing. Petr Ferfecki, PhD.:Department of Applied Mechanics, VSB - Technical University of Ostrava, 17. listopadu 15; 708 33, Ostrava; CZ, petr.ferfecki@vsb.cz and IT4Innovations National Supercomputing Center, VŠB-Technical University of Ostrava, 17. listopadu 15; 708 33, Ostrava-Poruba; CZ, petr.ferfecki@vsb.cz
} 
In this paper a new design concept of a hydrodynamic bearing lubricated by a composite magnetic fluid is reported. The carrying liquid is concentrated ferromagnetic fluid, in which ferromagnetic particles of a micrometer size are dispersed. The study is focused on the effect of control of magnetic properties of the lubricant on the bearing load capacity and vibration amplitude of rigid rotors loaded by constant forces and the rotor imbalance.

\section{Design concept of the proposed controllable hydrodynamic bearing}

The proposed hydrodynamic bearing consists of a bearing housing and of a central pin. The rotor journal is hollow and is inserted in the hole in the bearing housing. The lubricant is brought to the gap between the outer surface of the journal and the inner surface of the hole. The pin forms a core of a coil, which is a source of magnetic flux. The rotor journal is made of non magnetic material.

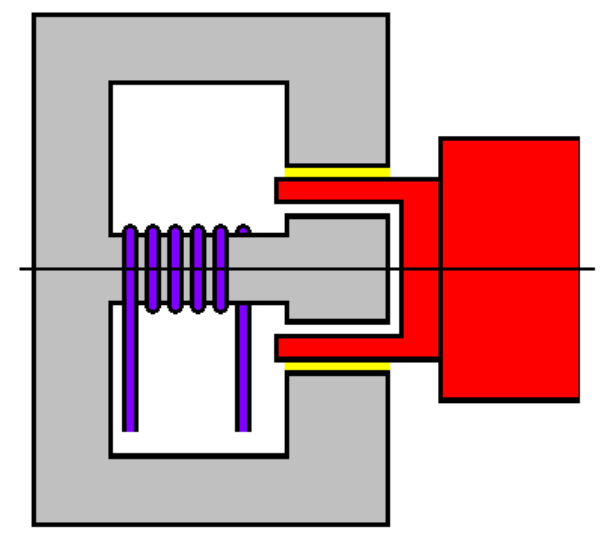

Fig. 1: Design concept of the proposed bearing.

The pressure distribution in the oil layer is described by the modified Reynolds equation derived on the following assumptions:

- the oil layer is divided in the sublayers in the radial direction,

- the liquid in each sublayer behaves as Newtonian,

- the applied boundary conditions require the velocity and the shear stress at location of the contact of two neighboring sublayers to be the same,

- the apparent viscosity in the individual sublayers is constant and is determined from the flow curve for the average sublayer velocity rate.

The apparent viscosity depends on magnetic induction, the magnitude of which is determined by means of the Hopkinson law (Ferfecki, 2017). In the areas of cavitation the pressure of the medium is assumed to remain constant. Components of the hydraulic forces are calculated by integration of the pressure distribution around the circumference and along the length of the bearing.

\section{Results of the simulations}

The analysed rotor is rigid (Fig 2). The controllable hydrodynamic bearings consist of two segments mutually separated by deep axial grooves, in which the lubricant is brought. The rotor rotates at constant angular speed and is loaded by the disc imbalance and by a force of constant magnitude acting on the disc in the vertical direction.

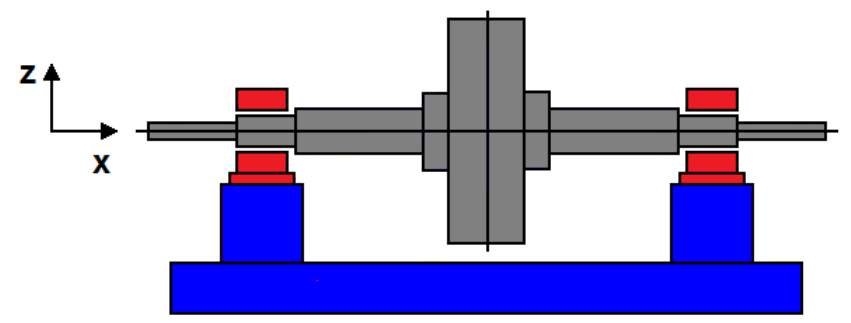

Fig. 2: Investigated rotor system. 
Lateral vibration of the rotor is governed by a set of two nonlinear motion equations

$$
\begin{gathered}
m \ddot{y}+b_{P} \dot{y}=m e_{T} \dot{\vartheta}^{2} \cos \vartheta+2 F_{h y} \\
m \ddot{z}+b_{P} \dot{z}=m e_{T} \dot{\vartheta}^{2} \sin \vartheta-m g+2 F_{h z}-F
\end{gathered}
$$

$m$ is the rotor mass, $b_{P}$ is the external damping coefficient, $e_{T}$ is the eccentricity of the rotor unbalance, $g$ is the gravity acceleration, $F_{h y}, F_{h z}$ are the y and $\mathrm{z}$ components of the hydraulic force acting on the rotor, $F$ is the constant force, $y, z$ are the displacements of the rotor center in the horizontal and vertical directions, $\vartheta$ is the angle of the rotor angular position, and (·), (*) denote the first and second derivatives with respect to time.

The principle parameters of the investigated rotor system are: rotor mass $430 \mathrm{~kg}$, eccentricity of the disc centre of gravity $50 \mu \mathrm{m}$, the bearing length $60 \mathrm{~mm}$, the shaft diameter $60 \mathrm{~mm}$, the bearing clearance $0.2 \mathrm{~mm}$, the oil viscosity (not effected by a magnetic field) 0.06 Pas and the number of the coil turns 900 .

Fig. 3 (left) shows the stationary positions of the journal center for angular velocity rising from 150 to $450 \mathrm{rad} / \mathrm{s}$ for the regime when no current was applied. The centers of the steady state orbits for the extent of velocities $150-550 \mathrm{rad} / \mathrm{s}$ and the applied currents $0.5,1.0$ and $1.5 \mathrm{~A}$ are depicted in Fig. 3 (right). It is evident that application of the current changes positions of the orbit centres in the bearing gap and pushes the orbits towards the bearing centre.
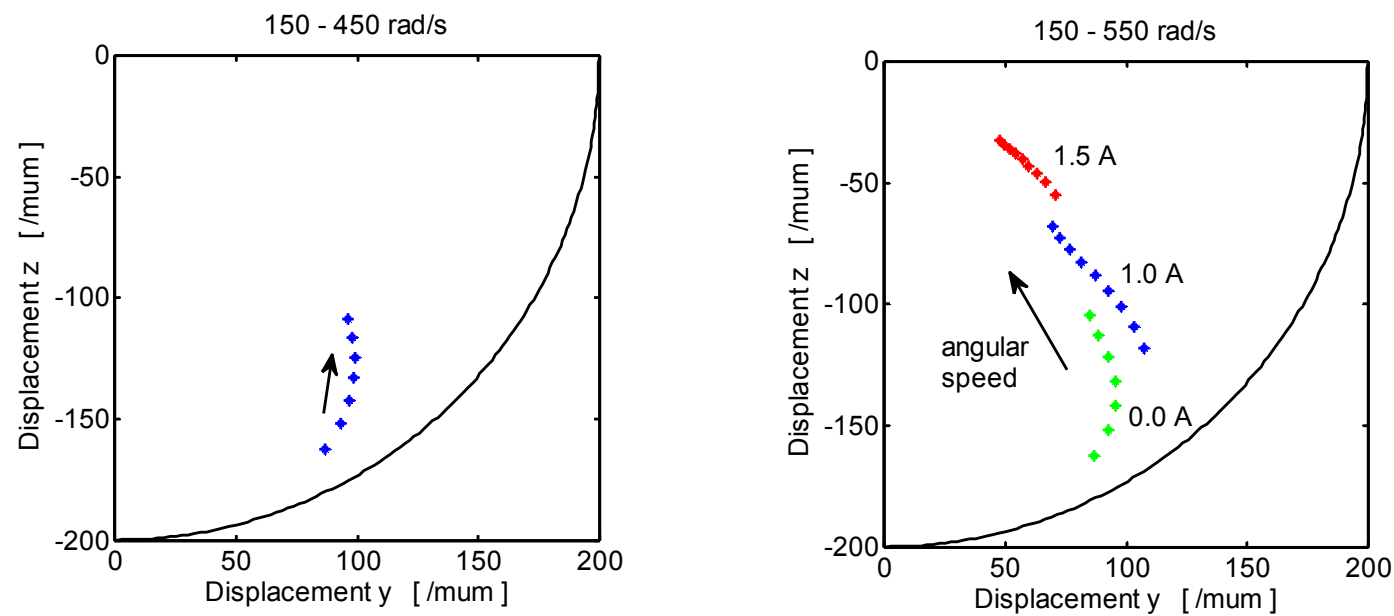

Fig. 3: Stationary positions (left) and orbit centrers (right) of the journal centre.

Fig. 4 (left) shows the steady state trajectories of journal centre for the speed of the rotor rotation $300 \mathrm{rad} / \mathrm{s}$ and rising applied current $0.5,1.0$ and $1.5 \mathrm{~A}$. The orbits are moving away from the edge of the bearing gap and approach to the bearing centre. The corresponding time history of the journal centre after switching the current on are drawn in Fig. 4 (right).
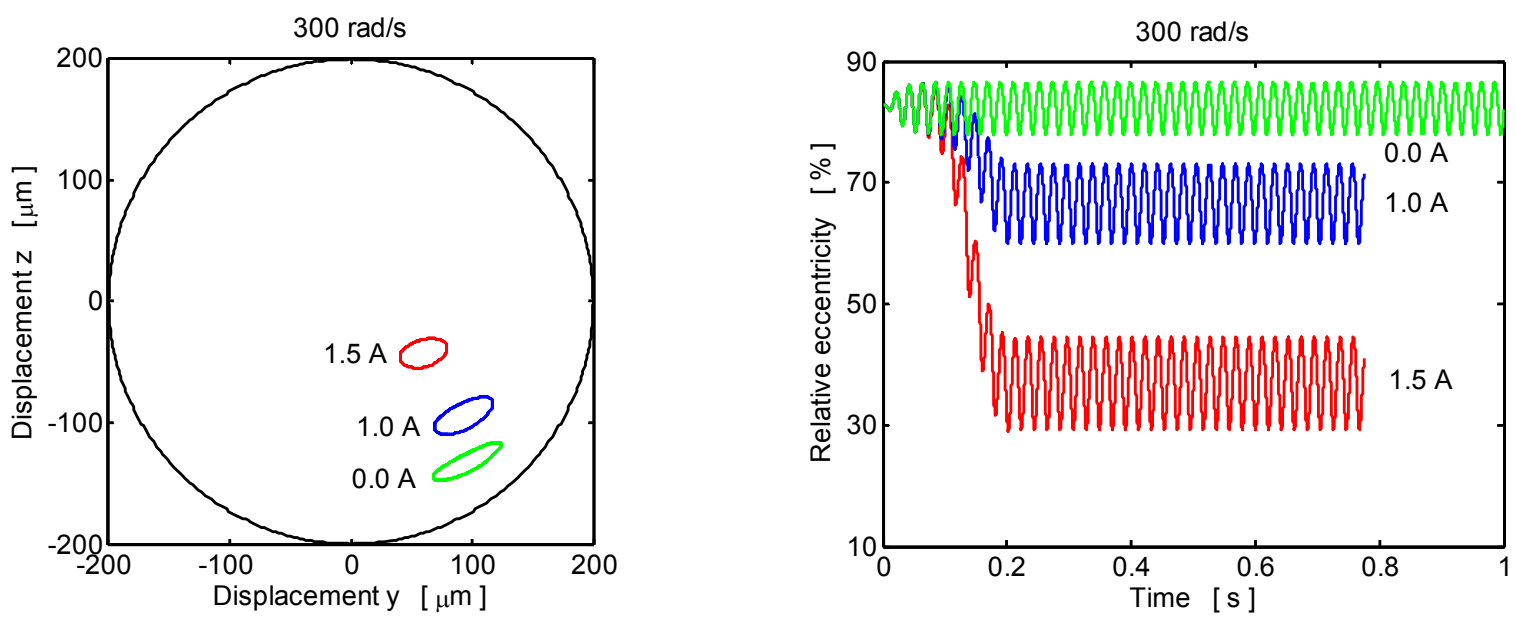

Fig. 4: The steady state orbits (left) and time history of the eccentricity (right) of the journal centre. 
Dependences of the peak to peak amplitude of the rotor vibration in the horizontal and vertical directions are drawn in Fig. 5. The results show that rising angular velocity increases the vibration magnitude and rising current leads to its reduction. It implies presence of a magnetic field increases stiffness of the oil film.
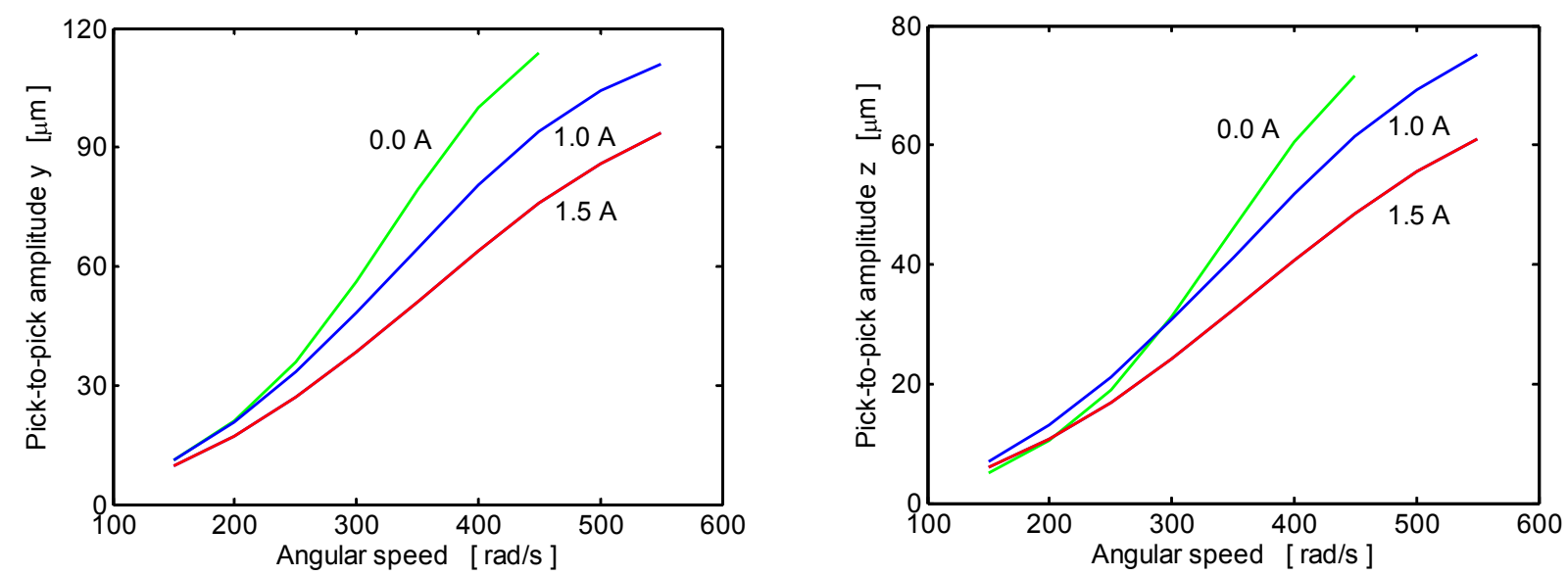

Fig. 5: Dependence of the pick-to-pich amplitude of speed of the rotor.

\section{Conclusions}

The main objective of the study was to analyse effect of the hydrodynamic bearings lubricated by magnetically sensitive fluids on their loading capacity and vibration amplitude of rigid rotors. The results of the computational simulations show that application of the magnetic field increases stiffness of the oil film. It arrives at increase of the bearing load capacity and reduction of amplitude of the rotor vibration.

\section{Acknowledgement}

The authors wish to acknowledge the support provided by the Czech Science Foundation (grant project 19-06666S) and by the Ministry of Education, Youth and Sports (the National Programme of Sustainability, NPU II, project LQ1602 - IT4Innovations excellence in science).

\section{References}

Bolek, A., Kochman, J. et al. (1989) Machine parts. SNTL, Prague (in Czech).

Ferfecki, P., Zapoměl, J., Kozánek, J. (2017) Analysis of the vibration attenuation of rotors sup-ported by magnetorheological squeeze film dampers as a multiphysical finite element problem. Advances in Engineering Software 104, pp. 1-11.

Susan-Resiga, D., Vékás, L. (2018) From high magnetization ferrofluids to nano-micro composite magnetorheological fluid: properties and applications. Romanian Reports in Physics, vol. 70, pp. 1-29.

Urreta, H., Leicht, Z., Sanchez, A., Agirre, A., Kuzhir, P., Magnac, G. (2010) Hydrodynamic Bearing Lubricated with Magnetic Fluids. Journal of Intelligent Material Systems and Structures, 21.

Wang, X., Li, H., Li, M., Bai, H., Meng, G., Zhang, H. (2015) Dynamic characteristics of magnetorheological fluid lubricated journal bearing and its application to rotor vibration control. Journal of Vibroengineering, 17, pp. 1912-1927. 